\title{
INTERPRETAÇÕES ALTERNATIVAS SOBRE A DESACELERAÇÃO E A CRISE BRASILEIRA A PARTIR DO INVESTIMENTO AGREGADO
}

\section{ALTERNATIVE INTERPRETATIONS ABOUT THE BRAZILIAN DECELERATION AND CRISIS FROM THE AGGREGATE INVESTMENT}

\author{
Thiago Rossi Silva* \\ Paulo Henrique Medeiros ${ }^{* *}$ \\ Hermano Caixeta Ibrahim ${ }^{* * *}$
}

\begin{abstract}
RESUMO
O objetivo deste trabalho é apresentar três visões alternativas sobre a interrupção do ciclo de crescimento no Brasil ocorrido em meados dos anos 2000, tendo como referência o papel central do investimento como guia do ciclo econômico. As visões serão abordadas levando em consideração seus aspectos políticos, discutindo pontos de encontro e desencontro entre elas, pontuando virtudes, complementariedades e lacunas das abordagens. A conclusão deste trabalho é de que as três visões estão em acordo sobre a relevância da disputa política para explicar a crise, porém diferem em aspectos pontuais sobre o início da crise e seus mecanismos de transmissão.
\end{abstract}

Palavras-Chave: economia brasileira; economia política; investimento; conflito distributivo.

\begin{abstract}
The aim of this paper is to present three alternative views on the interruption of the growth cycle in Brazil that occurred in the mid-2000s, with reference to the central role of investment as a guide of the economic cycle. The visions will be approached taking into consideration their political aspects, discussing points of encounter and mismatch between them, punctuating virtues, complementarities and gaps in the approaches. The conclusion of this paper is that the three views agree on the relevance of the political dispute to explain the crisis but differ in specific aspects about the onset of the crisis and its transmission mechanisms.
\end{abstract}

Keywords: Brazilian economy; political economy; investment; distributive conflict.

"Mestrando em Economia do Desenvolvimento pela Universidade Federal do Rio Grande do Sul

" Mestrando em Economia do Desenvolvimento pela Universidade Federal do Rio Grande só Sul

*** Doutor em Economia pela Universidade Federal do Rio Grande do Sul 


\section{INTRODUÇÃO}

Entre 2004 e 2010 o Brasil passou por um ritmo de crescimento acelerado, respaldado principalmente pela demanda externa. Este período foi caracterizado por queda do desemprego, aumento do rendimento real, aumento do crédito bancário e diminuição da pobreza e desigualdade (BARBOSA, 2010). Esse movimento fez com que o consumo das famílias (principalmente as de menor renda) crescesse consideravelmente, e com isso, o setor produtivo respondeu com um aumento do ritmo do investimento privado (ARESTIS, 2007).

Com a inversão do ciclo das commodities e a crise internacional que se inicia no segundo semestre de 2007, o setor privado, que agora não mais encontra uma demanda extra nas exportações, começa a encontrar suas primeiras dificuldades. Para sustentar seu ritmo de investimento, as empresas privadas passaram a se financiar utilizando capital de terceiros em maior quantidade, aumentando assim o seu endividamento líquido. Com a queda das receitas, o governo passou a operar em crescente déficit, posteriormente apontado como causa (e não efeito) da situação econômica pela visão tradicional (REZENDE, 2015).

Com a mudança no ciclo econômico, que começa com a desaceleração do produto brasileiro em 2011, muitas hipóteses sobre suas causas ganharam espaço no debate. Abordagens mais tradicionais, como a de Fraga (2016), apontam para a necessidade de buscar um equilíbrio fiscal, necessário para garantir o retorno da confiança dos agentes e, assim, retomar o ciclo de crescimento. Por outro lado, autores como Fonseca et. al (2018), Serrano e Summa (2018) e Marquetti et. al (2017) procuram explicar as mudanças ocorridas a partir de abordagens alternativas, onde a disputa política torna-se um aspecto central para explicar o movimento de declínio da economia brasileira.

Nessas visões alternativas, o papel da disputa entre grupos de interesse que portam maior capacidade de articulação se torna o ponto de partida, já que o crescimento do salário real acima da produtividade durante grande parte dos anos 2000 define a mudança na estratégia de política econômica do governo Dilma Rousseff em dois períodos: um período inicial em 2011 onde um conjunto de políticas que ficara conhecido como "nova matriz econômica" entra em vigor, caracterizado por redução da taxa de juros, depreciação do câmbio real, represamento de preços monitorados, isenções fiscais e subsídios a empresas selecionadas - posteriormente caracterizada como "campeãs nacionais". Em um segundo momento, a partir de 2014, a política se torna majoritariamente tradicional, com taxas de juros elevadas e cortes aos incentivos criados pela nova matriz macroeconômica.

O presente trabalho tem como objetivo comparar as visões alternativas de trabalhos que utilizam a leitura da economia política como chave para entender o processo de queda do investimento na economia brasileira. Desde o trabalho seminal de Keynes (1936), diferentes visões alternativas tomam o investimento como variável chave para definir os movimentos do ciclo econômico. As abordagens estudadas neste trabalho tentam explicar a dinâmica do investimento como forma de também explanar a dinâmica macroeconômica no período estudado.

A primeira hipótese, formulada por Fonseca et al. (2018), alega que as mudanças no investimento resultam da inversão na política de financiamento do BNDES e aumento das taxas de juros. Já a hipótese de Serrano e Summa (2018), irá defender que a inversão se deve a queda nos componentes autônomos da demanda, sendo estes responsáveis por guiar o movimento do investimento. Por último, a visão de Marquetti et al. (2017), alega que a queda do investimento decorre de uma compressão na taxa de lucro da economia, tornando os investimentos desinteressantes aos olhos dos empresários.

A primeira parte do trabalho irá se concentrar em expor as visões alternativas supracitadas. A segunda parte discutirá os pontos de convergência e divergência entre as visões, assim como a relevância das visões frente aos dados através de uma análise de estatística descritiva. Conclusões serão feitas ao final do texto.

\section{INTERPRETAÇÕES ALTERNATIVAS SOBRE A DESACELERAÇÃO E A CRISE BRASILEIRA}

\section{A interpretação de Fonseca et al (2018)}

Pela interpretação de Fonseca et al. (2018), as mudanças da política a partir de agosto de 2011 representaram um rompimento com o pacto de coalizão firmado pelo presidente Lula a partir da "Carta 
ao povo brasileiro", na qual, em 2002, ele sinaliza que não romperia com as políticas macroeconômicas de Fernando Henrique Cardoso. Eleita em 2010, a presidente Dilma Rousseff tenta alterar a forma de condução da política macroeconômica em agosto de 2011 a partir da implementação do que ficou conhecida como "nova matriz econômica", na qual houve uma flexibilização do regime de metas de inflação, redução da taxa básica de juros (SELIC) e desvalorização cambial. Esse movimento se deu mesmo com previsões realizadas pelo banco central que indicavam notória possibilidade de uma aceleração da inflação. Na visão do autor, essa mudança abrupta na condução da política econômica causou problemas para empresas que possuíam seus passivos em dólar e provocou perdas para grupos de interesse que se beneficiavam das políticas que vinham sido adotadas até então.

Além disso, houve diversas políticas verticais para determinados setores e empresas, as "campeãs nacionais", as quais receberam subsídios e isenções. Esse conjunto de políticas verticais podem ser vistas como um aprofundamento do intervencionismo estatal na economia a partir de linhas de financiamento fornecidas pelo BNDES. A questão da desvalorização cambial foi problemática para empresas industriais e financeiras com custos e endividamento em moeda estrangeira, resultando em uma direta oposição ao governo por parte da FIESP (Federação das Indústrias do Estado de São Paulo). Com a insustentabilidade do cenário, Dilma Rousseff tenta retomar a antiga agenda em seu segundo mandato, todavia, o descontentamento dos setores antes beneficiados pelo pacto de coalizão resultou no impedimento da presidente em 2016.

Para o autor, contrariamente à visão de Singer $(2015)^{1}$ não é possível considerar a "nova matriz econômica" como desenvolvimentista, já que esta surge como resposta à crise internacional e a queda dos preços das commodities, quebrando assim com os pressupostos do desenvolvimentismo ${ }^{2}$. As políticas adotadas a

\footnotetext{
${ }^{1}$ De forma sintética, a visão de Singer (2015) é a de que a virada no rumo das políticas econômicas realizadas por Rousseff a partir de 2011 com a "nova matriz", a então presidente tentou impor uma retomada do ciclo de crescimento dos governos Lula a partir do que ele denomina ensaio desenvolvimentista. Ele alega que houve tentativa de reindustrialização no período e este é o ponto principal de sua argumentação quanto à implementação de um plano desenvolvimentista no Brasil.

${ }^{2}$ Fonseca (2014) arrola três atributos que compõem o hard core do conceito de desenvolvimentismo. São eles: (1) planejamento, estratégia de desenvolvimento nacional (portanto, algo prévio à posse do mandato, não somente uma reação a cenários adversos), (2) intervenção estatal e (3) industrialização,
}

partir de 2011 tinham mais similitudes com políticas anticíclicas de reativação de oferta do que com uma tentativa de retomar uma estratégia de desenvolvimento. Sinais claros dessas políticas anticíclicas foram as tentativas de reduzir os custos das empresas através do represamento dos preços de energia elétrica e as reduções de IPI para a linha branca, aumentando o déficit público e, portanto, impossibilitando expansões da demanda agregada via incentivos do setor público ${ }^{3}$.

A hipótese apresentada defende que o declínio do investimento pode ser explicado a partir do descontentamento do setor industrial e financeiro com o crescente intervencionismo na economia e, como pontua Marquetti et al. (2017), um achatamento dos lucros que se inicia com a queda do ciclo das commodities e se agrava dada a redução na taxa de juros, a depreciação cambial e a queda das exportações devido à desaceleração da atividade econômica mundial posterior à crise de 2008 .

A insistência de políticas públicas de isenções ao setor privado e subsídios ao consumo das famílias causou uma exaustão nos recursos públicos, inviabilizando posteriormente qualquer tentativa de reativação da economia. Tal inviabilidade foi fruto da pressão realizada por grupos de interesse em promover um ajuste recessivo. O ajuste contou com elevação da taxa de juros e corte dos subsídios ao setor privado, resultando na queda dos investimentos privados - os quais deveriam ser o motor do crescimento.

\section{A INTERPRETAÇÃO DE SERRANO E SUMMA (2018)}

Na interpretação de Serrano e Summa (2018), a explicação para o caso brasileiro se baseia em duas hipóteses centrais que levam a uma resposta centrada no Supermultiplicador Sraffiano (SS) apresentado por Serrano, Freitas e Behring (2018). Para os autores, o movimento dos gastos exógenos à renda não geradores de capacidade instalada explica o movimento do investimento - ou seja, o investimento gerador de capacidade instalada é completamente induzido nessa abordagem. Para entender como o caso brasileiro está

\footnotetext{
abrindo espaço para maior convergência de renda, produtividade e estágio tecnológico com países mais ricos e desenvolvidos (catching up tecnológico). ${ }^{3} \mathrm{O}$ padrão de crescimento do governo Lula, antes assegurado pelo alto volume de exportações, investimento público e consumo interno, deixou de ser possível, fazendo o governo alterar sua estratégia de política econômica.
} 
relacionado com a hipótese do SS, é preciso explorar as duas hipóteses postas pelos autores.

A primeira hipótese é de que houve crescimento no poder de barganha dos trabalhadores, causando assim o que os autores irão chamar de "revolução indesejada" no mercado de trabalho. Esse crescimento do poder de barganha acontece entre 2004 e 2014, prosseguindo mesmo depois de 2011, quando a economia começa a desacelerar. Esta "revolução indesejada" proporcionou uma tendência de crescimento dos salários reais acima do crescimento da produtividade, acirrando progressivamente o conflito distributivo e reduzindo as margens e taxas de lucros das empresas.

Já a segunda hipótese, evidencia que a interrupção do processo de crescimento, acentuado em 2015, parte do acirramento do conflito distributivo. Esse efeito aconteceu de maneira indireta, já que a pressão política exercida sobre o governo tinha como objetivo mudar o regime de política econômica e solucionar o conflito distributivo a favor dos empresários. Para os autores, o processo de crescimento das economias é guiado pelos gastos autônomos não geradores de capacidade, o qual foi diretamente afetado pela mudança na condução de política econômica que tinha como objetivo resolver o conflito distributivo.

Um aumento dos salários reais acima do crescimento da produtividade tende a reduzir as margens de lucros das empresas. A partir desta redução, a taxa de lucro realizada sobre o estoque de capital fixo, que já está operante, tende a se reduzir, porém, a transferência de renda em direção a indivíduos com uma maior propensão marginal a consumir tende a atenuar o efeito negativo desta queda. Esse efeito tende a aumentar a demanda agregada, levando à maior utilização da capacidade instalada.

Tendo em mente as duas hipóteses apresentadas, é possível relacionar a explicação dos autores para o movimento do investimento com a hipótese do SS originalmente desenvolvido por Serrano (1995). Nessa perspectiva, é preciso compreender que o investimento é pautado pelo movimento dos componentes autônomos à renda que não geram capacidade instalada. Se um movimento de mudança no conflito distributivo é iniciado na esfera política, repercussões na condução de política econômica pode afetar negativamente a estrutura desses gastos - o que os autores alegam ter sido exatamente o que aconteceu no Brasil.
A equação fundamental do SS, derivada de um conjunto de equações Keynesianas ${ }^{4}$, é definida como:

$$
Y^{*}=\frac{Z}{s-v(d+g z)}
$$

Onde $\mathrm{Y}^{*}$ é a taxa de crescimento do produto potencial, $\mathrm{Z}$ é uma variável que condensa os gastos autônomos não geradores de capacidade instalada, s agrega os componentes da propensão marginal a poupar, v é a relação capital-produto, d o coeficiente de reposição e gz a taxa de crescimento dos componentes autônomos da demanda ${ }^{5}$. Dessa forma, é fácil perceber como se dá, algebricamente, a relação dos componentes exógenos não geradores de capacidade com a taxa de crescimento do produto potencial, assim como defendem os autores.

Resultados empíricos recentes estudaram se existem indícios de que a economia brasileira opera sob a hipótese do SS. Braga (2018) investiga a possibilidade de a economia brasileira operar sob a hipótese do acelerador e utilizou a estrutura do SS com um modelo VAR em um período entre 1967 e 2017. Os resultados sugerem que a hipótese do SS poderia explicar a situação brasileira, tanto para dados trimestrais como para dados anuais. Outro resultado interessante pode ser encontrado em Avancini (2015), onde o autor apresenta resultados semelhantes com um modelo VAR para o Brasil entre 1995 e 2015, utilizando dados trimestrais. Os resultados mostram uma forte relação entre a taxa de crescimento da demanda e a taxa de crescimento da formação bruta em máquinas e equipamento, corroborando mais uma vez com a hipótese defendida por Serrano e Summa (2018).

Em síntese, a visão dos autores evidencia que a queda do investimento na economia brasileira se deve a uma constante diminuição na taxa de crescimento dos componentes autônomos da demanda que não geram capacidade instalada. $\mathrm{O}$ crescimento dos salários reais acima da produtividade que aconteceu entre 2002 e 2014 minou a margem de lucro do empresariado, e

\footnotetext{
${ }^{4}$ A derivação completa do modelo pode ser encontrada em Serrano (1995), Cesaratto, Serrano e Stirati (2002), Freitas e Serrano (2015) e Serrano, Freitas e Behring (2018).

${ }^{5}$ Em uma versão para o produto efetivo, ou seja, o movimento da renda no curto prazo, a variável gz é substituída por uma variável ge que capta a expectativa de demanda. Como resultado do modelo, a taxa de crescimento potencial definida por $\mathrm{Y}^{\star}$ se ajusta a taxa efetiva $\mathrm{Y}$ através de um mecanismo do tipo "acelerador flexível" descrito por Chenery (1952). Para maiores informações consultar Serrano, Freitas e Behring (2018).
} 
com a queda da atividade econômica que se inicia em 2011, os grupos dominantes utilizaram da articulação na esfera política para mudar os rumos da política econômica, de forma a aumentar seus ganhos dentro do conflito distributivo. Como resultado dessa mudança política, a taxa de crescimento dos componentes exógenos foi dramaticamente afetada, reduzindo assim o investimento.

\section{A interpretação de Marquetti el al (2017)}

A ruptura da política econômica ocorrida em 2011 é fundamental para entender o esmagamento dos lucros, foco do estudo de Marquetti et al. (2017). A taxa de lucro, crescente entre 2003 e 2007, passa a declinar após a crise financeira internacional de $2008^{6}$. Todavia, no governo Rousseff, em 2011, houve acentuada queda da taxa de lucro em detrimento da redistribuição da renda em favor dos salários. Em conjunto, acontece o ciclo de redução da taxa de juros, indicando uma quebra do acordo de classes firmado por Lula.

Sendo a lucratividade a força motriz do capitalismo, para a tradição marxista, o autor argumenta que o investimento e a produção possuem finalidade da geração de lucro e reprodução do capital. Quando há queda da taxa de lucro, as expectativas de lucratividade também se reduzem, tendendo a diminuir os investimentos das empresas e, consequentemente, a acumulação de capital. Menor investimento significa menos emprego e produção. Por essa ótica, uma queda na taxa de lucro resulta em taxas mais baixas de crescimento, emprego e produção (MARQUETTI ET AL., 2017).

Para melhor entender o raciocínio de Marquetti et al. (2017), o trabalho de Weisskopf (1979) deve ser levado em consideração. O autor propôs a decomposição da taxa de lucro levando em consideração a parcela dos lucros na renda, $\pi$, o nível de utilização da capacidade instalada, $u$, e a produtividade potencial do capital $\rho$. Dessa forma, a taxa de lucro é expressa da seguinte forma:

$$
r=\frac{\frac{\bar{X}^{X} * X p}{K} * X}{X p}=\pi \rho u
$$

\footnotetext{
${ }^{6}$ Mesmo em tal cenário, a taxa se mantinha mais elevada do que a observada no começo do século (Marquetti et al., 2017).
}

sendo $\mathrm{r}$ a taxa de lucro líquida, $\mathrm{Z}$ o montante de lucro líquido, K o estoque de capital líquido não residencial, $\mathrm{X}$ o produto líquido e Xp o produto líquido potencial.

Weisskopf (1979) elenca três fatores que podem originar crises, pela ótica marxista. O primeiro é a redução da parcela dos lucros na renda devido ao fortalecimento do poder de barganha da classe trabalhadora, elevando os salários acima do aumento da produtividade do trabalho. O segundo é

“(...) a redução da produtividade potencial do capital devido ao aumento da composição orgânica do capital. Esse fenômeno ocorre devido à elevação dos preços dos bens de investimento em relação aos demais bens e, em uma economia aberta, pela queda dos termos de troca." (MARQUETTI ET AL., 2017, p. 5-6).

O terceiro é a queda do nível de utilização da capacidade instalada decorrente de contração da demanda agregada.

Para o Brasil, Marquetti et al. (2017) encontra os três fatores sendo responsáveis pela queda do produto e do emprego, principalmente nos dois primeiros. A queda na parcela dos lucros, já explicitada anteriormente como resultado do aumento da parcela salarial e dos salários mínimos sem contrapartida da produtividade do trabalho, praticamente constante durante o período em análise. Quanto ao aumento da composição orgânica do capital, o autor afirma que, a partir de 2014, com déficits públicos politicamente insustentáveis, queda da demanda mundial por commodities, - portanto, do preço delas - e a própria queda da taxa de lucro causaram uma deterioração dos termos de troca ${ }^{7}$. A queda da utilização da capacidade instalada observada a partir de 2013 é vista como fruto de uma demanda agregada reprimida devido à queda contínua da taxa de lucro, resultando em menos investimentos privados.

Um ponto importante salientado por Marquetti et al. (2017) é de que os déficits públicos a partir de empréstimos subsidiados do BNDES, swaps cambiais e represamento do reajuste de tarifas administradas, como energia elétrica, combustíveis e transporte público não só tolheu a capacidade de investimentos

\footnotetext{
${ }^{7}$ Importante mencionar também o esforço em combater a inflação a partir de swaps cambiais em 2014 para que não houvesse depreciação cambial forte, que seria transmitida para os preços a partir do encarecimento de máquinas e equipamentos (Marquetti et al., 2017).
} 
públicos ${ }^{8}$ devido a sucessivos déficits a partir de 2014, mas também tais déficits, na tentativa de reativar a oferta da economia via subsídios e isenções fiscais, foram absorvidos pelas empresas na forma de lucro.

A insustentabilidade de tais políticas foi observada em 2015, quando uma virada no rumo da economia foi forçada com políticas neoliberais de aumento da taxa de juros e desvalorização cambial na tentativa de segurar a inflação. Todavia, uma desvalorização cambial de $47,02 \%$ em 2015 e aumento de 51\% na tarifa de energia elétrica residencial em 2015 elevaram a inflação para $11,07 \%$ ao final de 2015 . Houve também forte restrição ao crédito, principalmente para pessoa física, corroborando com a contração da demanda agregada.

Com isso, a taxa de lucro e a profit share apresentaram elevação em 2015, às custas do pagamento de juros da dívida pública cada vez maiores devido ao ciclo de aumento da meta da taxa de juros SELIC. Apesar disso, o descontentamento por diversas parcelas da sociedade, tanto mais alinhadas à esquerda quanto à direita, tornaram insustentável a governabilidade de Dilma Rousseff, tendo havido abertura do processo de impedimento em dezembro de 2015 e afastamento do cargo de presidente em 2016.

\section{DISCUSSÃO}

As visões alternativas abordadas neste texto partem de um mesmo ponto chave: a economia brasileira passou por um contínuo crescimento do salário real acima da produtividade, acirrando assim o conflito distributivo entre capital e trabalho. Este ponto é fundamental, já que as repercussões políticas e econômicas são responsáveis por construir, ao longo do tempo, um processo de fragilização do pacto social firmado em 2002. Segue abaixo o comportamento do salário real e da produtividade do trabalho entre 2002 e 2015:
Figura 1 - O salário médio real e a produtividade líquida do trabalho, Brasil, 2000-2015

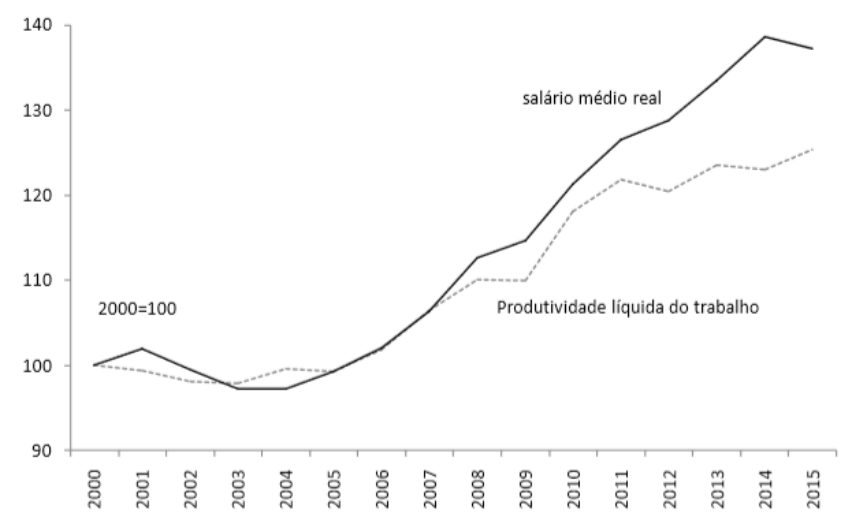

Extraído de: MARQUETTI ET AL. (2017).

Como observado nos dados, de fato o movimento do salário real passa a crescer consideravelmente acima da produtividade a partir de 2007, corroborando com o ponto de convergência explicitado pelos autores. O problema do descolamento destacado pelos dados se dá na estrutura de custos das firmas, já que um crescimento do salário pago pelas firmas significa um crescimento dos seus custos. Por outro lado, uma produtividade que não acompanha o crescimento dos custos significa que o resultado do trabalho cresce abaixo de seu pagamento. Esse movimento pode ser visualizado diretamente como uma transferência de renda em direção ao trabalho. A figura abaixo exibe o comportamento da participação dos lucros e salários na renda nacional:

Figura 2 - Parcela de lucro e a parcela do salário, Brasil, 2000-2015

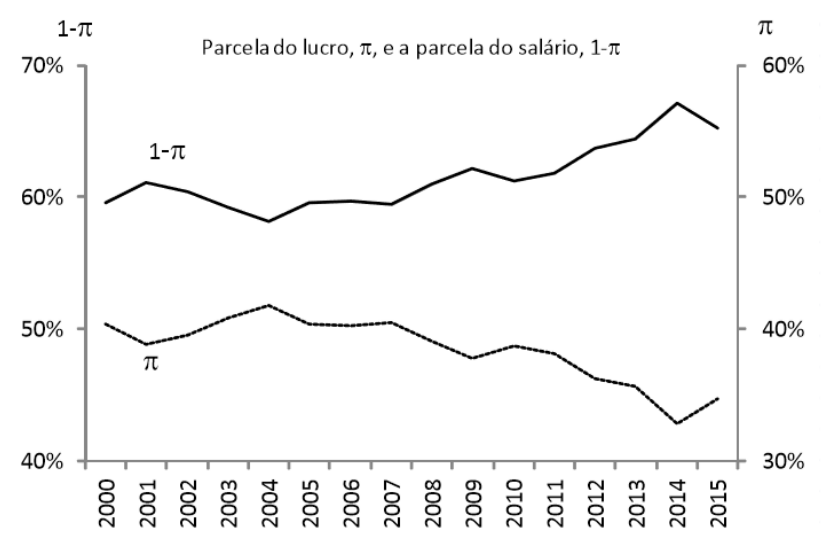

Extraído de: MARQUETTI ET AL. (2017).

A expansão da parcela salarial de forma quase contínua de 2008 a 2014 gerou conflitos de classes e insatisfação principalmente por parte da classe

${ }^{8}$ A queda do preço internacional do petróleo causou prejuízos à Petrobras, empresa com maior participação nos investimentos nacionais. 
capitalista da sociedade. Singer (2015) descreve tal conflito como "silencioso", latente sem que o governo Rousseff tivesse percebido até 2013, ano em que os mais diversos setores da população foram às ruas ${ }^{9}$, quando o autor julga ter sido tarde demais para a então presidente.

Todas as visões abordadas concordam que o movimento da queda da participação dos lucros na renda e queda da taxa de lucro gerou uma insatisfação por parte dos proprietários do capital, porém, os desdobramentos gerados passam a divergir quanto a explicação de como esse efeito passa a afetar o investimento. Em um primeiro passo, é preciso investigar a hipótese levantada por Fonseca et al. (2018) de que o investimento produtivo respondeu negativamente à elevação da taxa de juros e a queda dos desembolsos do BNDES. Segue abaixo figura exibindo o dos desembolsos do BNDES e da formação bruta de máquinas e equipamentos ${ }^{10}$ :

Figura 3 - Desembolsos do BNDES (\%) e variação real da FBME (\%).

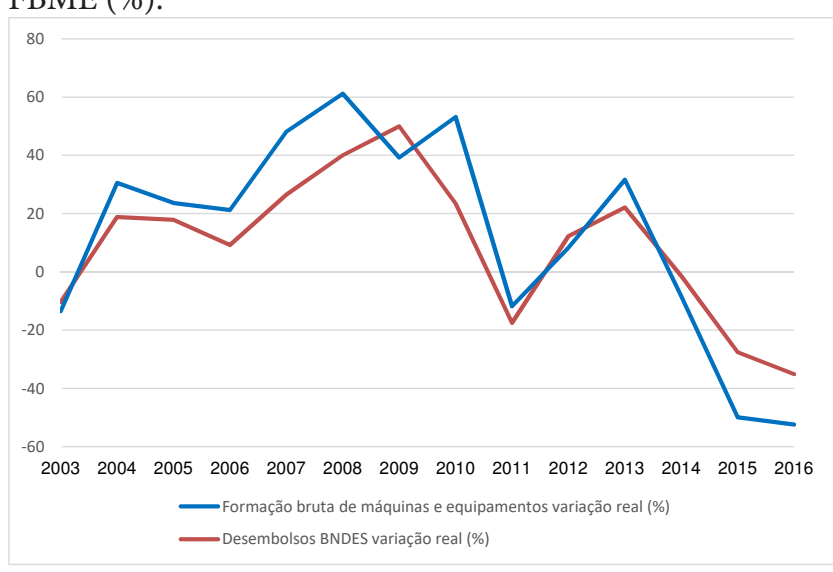

Fonte: BNDES e IBGE. Elaboração própria.

A explicação fornecida por Fonseca et al. (2018) está em acordo com a visão de Serrano e Summa (2018) sobre a natureza política da crise, porém a explicação dos desdobramentos econômicos que afetaram o investimento recai exclusivamente em fatores do lado da oferta. O gráfico acima mostra uma resposta do investimento com descasamentos a partir de 2007, ou seja, a resposta da formação bruta de máquinas e

\footnotetext{
${ }^{9}$ Singer (2015) afirma que tanto setores de esquerda como de direita estiveram presentes nas manifestações, de estudante até a classe alta, de operários a industriais insatisfeitos com as políticas intervencionistas da "nova matriz".

${ }^{10} \mathrm{~A}$ variável formação bruta de máquinas e equipamentos foi selecionada com o intuito de capturar o investimento produtivo realizado pelas empresas, já que a série de investimento das contas nacionais inclui também infraestrutura e construção civil.
}

equipamentos não responde diretamente as variações, incluindo o pico que ocorre em 2010, momento em que os desembolsos já estavam em queda acentuada. No momento referente a "nova matriz econômica", as duas séries seguem trajetórias similares, porém com uma desaceleração mais rápida da formação bruta de máquinas e equipamentos a partir de 2014 .

O movimento dos desembolsos do BNDES parece estar de acordo com a visão de Fonseca et al. (2018), porém é importante salientar que não é possível retirar qualquer causalidade entre as séries, e sim apenas enfatizar que houve um movimento que, a priori, está dentro do esperado. Também é importante entender até que ponto as variações conseguem explicar as mudanças, i.e., não há como saber, a priori, o impacto preciso dos desembolsos sobre o investimento privado. Para complementar a análise, também é preciso observar o movimento que acontece na taxa SELIC descrito pelo autor em relação a mesma série de formação bruta de máquinas e equipamentos ${ }^{11}$ :

Figura 4 - Taxa SELIC a.a. (\%) e Formação bruta de máquinas e equipamentos - variação real (\%)

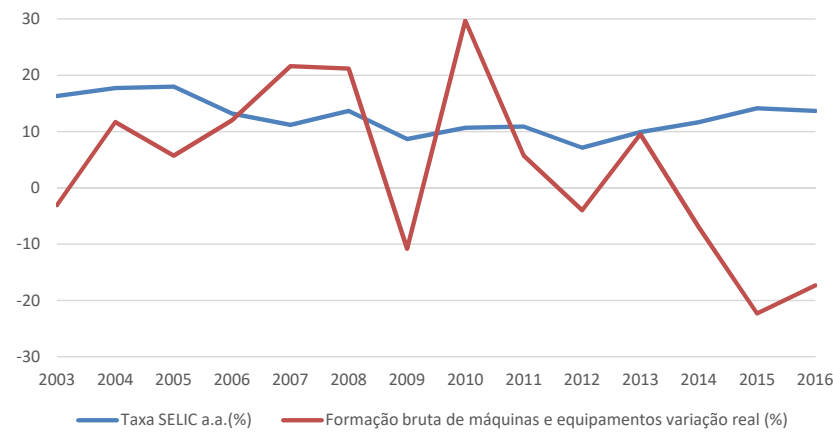

Fonte: BCB e IPEA. Elaboração própria.

Neste caso, a taxa SELIC parece não refletir de forma clara as mudanças na formação de máquinas e equipamentos. Mais uma vez é preciso ter cuidado com a análise gráfica simples, esta não refletindo causalidade nem capturando, de maneira precisa, o impacto de uma variável sobre outra. A abordagem de Fonseca et al. (2018) leva ao lado da oferta a variação no investimento, porém, essa visão pode ser complementada com fatores relacionados ao lado da demanda como poderemos ver abaixo.

\footnotetext{
${ }^{11}$ Esse gráfico segue a análise descrita pelo autor, porém, é comum neste caso utilizar a taxa de juros real ou uma taxa de juros de longo prazo como forma de relacionar juros e investimento.
} 
Na visão de Serrano e Summa (2018), o movimento inicial de crescimento dos salários, chamado pelos autores de "revolução indesejada", atinge o investimento de maneira indireta. Em um primeiro momento, a partir de 2011, os autores advogam que a mudança na condução da política econômica (pleiteada na esfera política) em direção a "nova matriz econômica" não conseguiria acelerar o ritmo do investimento, já que as tentativas de ativar a economia foram feitas exclusivamente através dos fatores de oferta, e na visão dos autores o investimento responde diretamente as mudanças nos componentes autônomos da demanda que não geram capacidade instalada na economia. Segue abaixo figura contendo o movimento dos principais componentes autônomos ${ }^{12}$ e do investimento produtivo:

Figura 5 - Formação brutal de máquinas e equipamentos - variação real (\%) e componentes autônomos da demanda - variação real (\%)

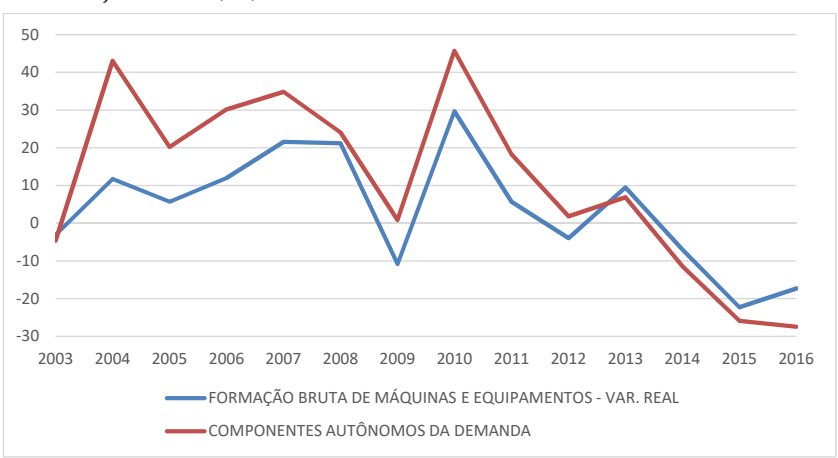

Fonte: IpeaData. Elaboração própria.

É possível visualizar um comportamento muito similar das duas séries a partir de 2009, porém, o mesmo não é verdade até 2007. Em trabalhos empíricos como Avancini (2015) e Braga (2018) os autores indicam que a hipótese do SS não explica de maneira eficiente o funcionamento da economia brasileira entre 2004 e 2007. Para o problema estudado neste trabalho, podemos observar uma relação muito próxima e que também é corroborada pelos testes econométricos descritos acima.

Com essas duas visões, podemos relacionar que os fatores de restrição de crédito apresentados por Fonseca et al. (2018) podem ser parte da explicação da dinâmica do investimento, enquanto os fatores de demanda também explicam grande parcela. Uma maneira de enxergar melhor essa explicação sob ambas óticas, de oferta e demanda, é entender que diferentes setores da economia operam sobre diferentes incentivos e restrições, ou seja, cada setor pode ter sido influenciado de maneira diferente, gerando um resultado agregado que corrobora com ambas as visões. Para alcançar um resultado mais robusto é necessário ainda elaborar uma estratégia de identificação econométrica para auferir com maior clareza os efeitos isolados de cada variável.

Outro fator importante já mencionado é de que o pagamento de títulos da dívida pública com taxas de juros mais elevadas a partir de 2015, no segundo mandato Rousseff, foram para as empresas em forma de lucro, como aponta Marquetti et al. (2017), a partir de capitalização no mercado financeiro. Logo, houve transferência de renda do setor público para o privado sem retorno significativo para a sociedade em forma de investimentos produtivos que visam reduzir a capacidade ociosa, gerando mais empregos e, por via de efeito multiplicador, expandir a demanda agregada e a renda. Justamente os empresários não viram necessidade de investir na produção tendo ganhos elevados e garantidos pelo governo sobre o pagamento da dívida pública.

Para a visão de Marquetti et al. (2017), a compressão dos lucros foi o fator determinante para a redução do investimento. Como podemos notar nas figuras anteriores, o movimento de expansão dos salários se inicia em 2007, porém a formação bruta de máquinas e equipamentos não acompanha esse ritmo, chegando a crescer em alguns momentos. A princípio nos parece que a posição defendida por Marquetti et al. (2017) é equivocada, porém, dada a especificação da taxa de lucro de Weisskopf (1979), a utilização da capacidade instalada também é uma parte importante para definir a taxa de lucro. Segue abaixo figura que especifica a utilização da capacidade instalada:

\footnotetext{
${ }^{12}$ Os componentes autônomos selecionados foram: consumo do governo, exportações, formação bruta de capital fixo - construções e consumo de bens duráveis (esta como proxy para o consumo que não depende da renda).
} 
Figura 6 - Utilização da capacidade instalada na indústria

$(\%)$

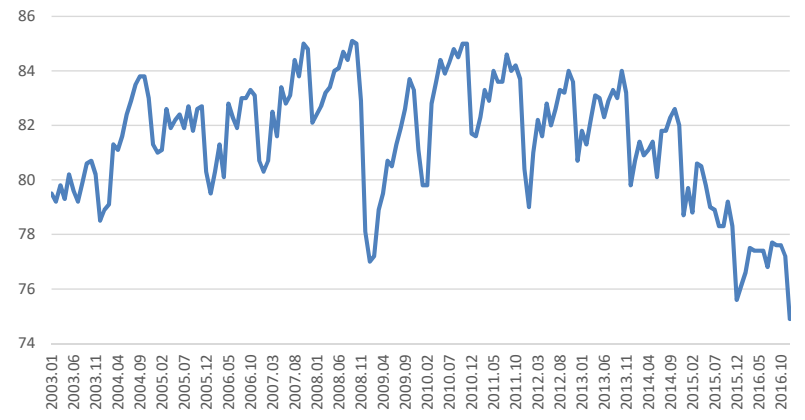

Fonte: IpeaData. Elaboração própria.

É possível observar um ritmo de aquecimento na economia, caracterizado por uma alta utilização da capacidade produtiva da economia, atenuando o efeito negativo da queda da participação dos lucros na renda. É possível perceber que a utilização da capacidade instalada reflete também o comportamento para a demanda. Dentro da tradição de Keynes (1936) a utilização da capacidade instalada depende das decisões de produção de curto prazo, essas refletindo a demanda pela produção, incluindo variação nos estoques consolidados pelas firmas.

A visão de Marquetti et al. (2017) rompe com os outros autores no momento em que o movimento de queda do investimento deriva da queda da taxa de lucro, ou seja, trata-se de um efeito econômico que foi intensificado pelas mudanças na condução da política. Para Fonseca et al. (2018) e Serrano e Summa (2018), por outra via, o efeito se inicia na esfera política e é transmitido pela economia através dos mecanismos do tipo acelerador e multiplicador. É possível perceber um desacordo dos autores em relação ao motor da desaceleração e seus mecanismos de transmissão. Segue abaixo um quadro resumo do que é apontado pelos autores:

\begin{tabular}{|l|l|l|l|}
\hline Trabalho & Hipótese & Inicio & Natureza \\
\hline Fonseca et al. (2018) & $\begin{array}{l}\text { Queda dos desembolsos } \\
\text { do BNDES; Elevação da } \\
\text { SELIC }\end{array}$ & $\begin{array}{l}\text { Quebra do pacto firmado em 2002; } \\
\text { pressão de grupos de interesse }\end{array}$ & Natureza política \\
\hline Serrano e Summa (2018) & $\begin{array}{l}\text { Queda dos componentes } \\
\text { autônomos da demanda }\end{array}$ & $\begin{array}{l}\text { Resolução do conflito distributivo; } \\
\text { pressão de grupos de interesse }\end{array}$ & $\begin{array}{l}\text { Natureza política que se converte } \\
\text { em efeitos econômicos }\end{array}$ \\
\hline Marquetti et al. (2017) & Queda da taxa de lucro & $\begin{array}{l}\text { Diminuição gradual na rentabilidade } \\
\text { dos investimentos }\end{array}$ & $\begin{array}{l}\text { Natureza econômica que se } \\
\text { converte em efeitos políticos }\end{array}$ \\
\hline
\end{tabular}

Dessa forma, observamos que as visões alternativas abordadas neste trabalho estão muito próximas inicialmente, porém tendem a analisar o cenário de maneira diferente e até mesmo com causa e efeito inverso.

\section{CONCLUSÃO}

As explicações para a trajetória de queda do investimento apresentadas neste trabalho mostram, apesar de diferenças, um papel importante da questão política. A quebra do pacto descrita em Fonseca et al. (2018), a "revolução indesejada" apontada por Serrano e Summa (2018) e o aumento de poder de barganha do trabalho e consequente queda da taxa de lucro contida em Marquetti et al. (2017) caracterizam a necessidade de introduzir fatores políticos dentro da análise de política econômica. Para todas as visões a noção de conflito está sempre presente, onde a apropriação da renda gerada é disputada entre capital e trabalho.

Os desdobramentos dentro da economia podem exibir distintas recomendações de política econômica de acordo com cada visão, porém, é necessário desenvolver trabalhos futuros abordando o possível impacto de cada conjunto de soluções que possam se basear nas leituras feitas neste trabalho.

Uma notória dificuldade foi utilizar apenas estatística descritiva e não métodos mais refinados para analisar os dados. Trabalhos futuros podem se beneficiar do que foi apresentado até o momento na forma de expandir os resultados para modelos econométricos, podendo auferir resultados mais apurados em relação a significância estatística, impacto e causalidade temporal.

As visões parecem explicar a crise de maneira parcial, porém, é entendido que essa forma de construção de pesquisa não necessariamente exige que outras visões sejam completamente descartadas. A trajetória 
histórica das economias está em constante mudança, e com isso é possível perceber que múltiplas formas de explicar os fenômenos são bem-vindas para consolidar o conhecimento sobre o tema estudado.

\section{REFERÊNCIAS}

ARESTIS, P.; DE PAULA, L. F.; FERRARI, F. Assessing the economic policies of President Lula da Silva in Brazil: has fear defeated hope?. Political economy of Latin America: recent economic performance. Basingstoke: Palgrave Macmillan, 2007.

AVANCINI, D.; FREITAS, F.; BRAGA, J. Investimento e Crescimento Liderado Pela Demanda: um estudo para o caso brasileiro com base no modelo do Supermultiplicador Sraffiano. Anais da ANPEC, 2015.

BANCO CENTRAL DO BRASIL. Histórico das taxas de juros. Disponível em: https:/www.bcb.gov.br/ controleinflacao/historicotaxasjuros. Acesso em: 23 ago. 2019.

BANCO NACIONAL DE DESENVOLVIMENTO ECONÔMICO E SOCIAL. Desembolsos do BNDES. Disponível em: https://www.bndes.gov.br. Acesso em: 23 ago. 2019.

BARBOSA, N. Latin America: counter-cyclical policy in Brazil: 2008-09. Journal of Globalization and Development, 2010, Vol. 1, No. 1.

BRAGA, J. Investment rate, growth and accelerator effect in the supermultiplier model: the case of Brazil. Textos para Discussão, n. 332, 2018.

CESARATTO, S.; SERRANO, F.; STIRATI, A. Technical change, effective demand and employment. Review of political economy, 2003, Vol. 15, No. 1, p. 33-52.

CHENERY, H. B. Overcapacity and the acceleration principle. Econometrica: Journal of the Econometric Society, 1952, Vol. 20, No. 1, p. 1-28.

FONSECA, P. C. D. Desenvolvimentismo: a construção do conceito, em André B. Calixtre, André M. Biancarelli, and Marcos Antonio M. Cintra (org.), Presente e Futuro do Desenvolvimento Brasileiro. Brasília: IPEA, 2014.

FONSECA, P. C. D.; AREND, M.; GUERRERO, G. A. Política econômica, instituições e classes sociais: Os governos do Partido dos Trabalhadores no Brasil, 2018.

FREITAS, F.; SERRANO, F. Growth rate and level effects, the stability of the adjustment of capacity to demand and the Sraffian supermultiplier. Review of Political Economy, 2015, Vol. 27, No. 3, p. 258-281.
Instituto Brasileiro de Geografia e Estatística. Séries estatísticas e históricas. Disponível em: https:// seriesestatisticas.ibge.gov.br. Acesso em: 23 ago. 2019.

IpeaData. Disponível em: https://ipeadata.gov.br. Acesso em: 23 ago. 2019.

KEYNES, J. The General Theory of Employment, Interest and Money. London, Palgrave Macmillan, 1936.

MARQUETTI, A.; HOFF, C. e MIEBACH, A. Lucratividade e Distribuição: A Origem Econômica da Crise Política Brasileira. XXII Encontro Nacional de Economia Política. Campinas, 2017.

Rezende, F. Why Does Brazil's Banking Sector Need Public Banks? What Should BNDES Do? Levy Economics Institute of Bard College Working Paper, 2015, No. 825.

SERRANO, F. Long period effective demand and the Sraffian supermultiplier. Contributions to Political Economy, 1995, Vol. 14, No. 1, p. 67-90.

SERRANO, F.; FREITAS, F.; BEHRING. G. The Trouble with Harrod: the fundamental instability of the warranted rate in the light of the Sraffian Supermultiplier, Working Paper 018|2017. Instituto de Economia/UFRJ, 2017.

SERRANO, F.; SUMMA, R. Conflito distributivo e o fim da "breve era de ouro" da economia brasileira. Novos estudos, 2018, Vol. 37, No. 2, p. 175-189.

SINGER, A. Cutucando onças com varas curtas: o ensaio desenvolvimentista no primeiro mandato de Dilma Rousseff (2011-2014), Novos estudos, 2015, Vol. 34, No. 2, p. 39-67.

WEISSKOPF, T. Marxian crisis theory and the rate of profit in the postwar US economy. Cambridge Journal of Economics, 1979, Vol. 3, No. 4, p. 341-378. 